\title{
MUTAÇÕES NA LEITURA: A INTERTEXTUALIDADE COMO MARCA NA LITERATURA INFANTIL CONTEMPORÂNEA
}

\section{READING MUTATIONS: INTERTEXTUALITY AS A MARK IN CONTEMPORARY CHILDREN'S LITERATURE}

\author{
MARTINS, Elaine Cristina da silva Martins \\ elainemartinsitj@hotmail.com \\ UNIVALI - Universidade do Vale do Itajaí \\ NEITZEL, Adair de Aguiar \\ neitzel@univali.br \\ UNIVALI - Universidade do Vale do Itajaí \\ FREITAS, Aline Amaral \\ alineamaralartes@gmail.com \\ UNIVALI - Universidade do Vale do Itajaí
}

RESUMO O livro de literatura infantil tem passado por transformações quanto à forma. Assim, este artigo tem como objetivo analisar duas obras de literatura infantil contemporânea - Felpo Filva e Abrindo Caminho - guiado pela questão problema: Como essas obras exploram a intertextualidade? A metodologia de pesquisa é qualitativa e a análise das obras teve em vista a classificação de transformação ou assimilação de Genette (1982) para revelar as marcas que atestam a presença de outros textos. Como resultados, indicamos: a) Felpo Filva é um livro que explora a intertextualidade por meio da citação; b) Abrindo Caminhos é um livro que optou pela alusão e pela citação indireta. Concluímos que uma narrativa tramada pelo viés da intertextualidade tende a ser mais aberta e a provocar uma leitura mais dinâmica.

Palavras-chave: Intertextualidade. Literatura infantil contemporânea. Mutações na leitura.

ABSTRACT Literature books for children have undergone transformations in relation to form. Thus, this paper aims to analyze two works of contemporary children's literature - Felpo Filva and Abrindo Caminho - guided by the problem question: How do these works explore intertextuality? The research methodology is qualitative and the analysis of the works had in mind Genette's (1982) transformation or assimilation classification to reveal the marks that attest the presence of other texts. As results, we indicate:a) Felpo Filva is a book that explores the intertextuality through quotation; b) Abrindo caminho is a book that opted for allusion and indirect quotation. We conclude that a narrative that carries intertextuality tends to be more open and provoke a more dynamic reading.

Keywords: Intertextuality. Contemporary children's literature. Reading mutations. 


\title{
1 INTRODUÇÃO
}

\begin{abstract}
[...] ler significa despojar-se de toda intenção e todo preconceito para estar pronta a captar uma voz que se faz ouvir quando menos se espera, uma voz que vem não se sabe de onde, de algum lugar além do livro, além do autor, além das convenções da escrita: do não - dito, daquilo que o mundo ainda não disse sobre si e ainda não tem as palavras para dizer.
\end{abstract} Ítalo Calvino

Calvino (1999a, p. 243) apresenta em sua obra Se um viajante numa noite de inverno uma narrativa que salienta que os textos provocam o leitor a um tipo de leitura relacional em maior ou menor grau. A epígrafe acima suscita a ideia do texto como uma trama relacional e dinâmica, um conjunto informacional dinâmico e expansível composto de textos verbais e/ou não verbais. A intertextualidade encontra-se fundada em ideias de plurivocidade do texto, sinalizando sua expansão pela conexão com outros textos. Ela se constrói por meio de um processo relacional, textos que murmuram outros textos, que são lidos em relação a outros, que são modelados pelo autor e re-inventados pelo leitor - "todo livro nasce na presença de outros livros, em relação e em confronto com outros livros" (CALVINO, 1999a, p. 266).

A afirmação de Genette que apenas a Odisséia de Homero apresenta originalidade, sendo esta obra o palimpsesto de todas as outras; evoca a ideia de que não há como se despir da marca do outro, de que toda construção textual se estrutura de forma combinatória e atesta a presença do outro e, por isso, apresenta uma textualidade múltipla que indica direções de leitura possíveis. Entretanto, a potencialidade intertextual dos textos varia; por exemplo, as escolhas dos autores podem ser pela citação explícita, escancarando ao leitor o processo de comunicação com outros textos, ou poderá optar pela alusão, que invoca de forma mais implícita. A intertextualidade é o resultado de um embricamento de textos por meio de imitações, paródias, citações, plágios, traduções, reminiscências, paratextos, pastiches, alusões, críticas, paráfrases, entre outros.

Segundo Neitzel (2009), esse processo quanto mais transgressor mais rico será, porque ele implicará na re-significação da obra precursora. Essa transgressão evidencia-se pela exploração da intertextualidade, cujo grau de explicitação pode ser maior ou menor, de forma velada (e até não intencional) ou explícita, mostrando o texto ao leitor como mosaico composto de outros textos. Independentemente do uso 
dos intertextos, a intertextualidade se constitui como um trabalho de transformação e assimilação de vários textos; no entanto, quando ele oferece uma composição multidimensional e multi-sequencial que nos permite entrar e sair por várias possibilidades de leitura, em uma estrutura em rede, a intertextualidade colabora para a abertura do texto, para que ele se torne um texto plural e escrevível no sentido atribuído por Barthes (1997).

Um texto construído em rede com outros textos apresenta uma organização acumulativa, modular e combinatória e, por isso, propõe ao leitor um jogo interativo, um convite a navegar pelos intertextos estabelecendo conexões, atribuindo sentidos, a leitura como jogo, montagem. Esta passou a ser uma das características da literatura contemporânea, a exploração dos intertextos em relevo, fragmentando o texto, causando cissuras na leitura, introduzindo o processo de leitura aos saltos. Também a literatura infantil se vê hoje envolta nesse movimento, e a criança - de leitora de fábulas moralizantes que explicitam verdades -, passa a ser desafiada por esse texto plural e escrevível que revela as marcas do outro, que convida a uma leitura relacional, estimulando-a a ler em uma outra dinâmica, o que atesta mutações no processo de escrita e de leitura.

Diante disso, este artigo objetiva problematizar como a intertextualidade é trabalhada em duas obras infantis: Felpo Filva, de Eva Furnari, e Abrindo Caminho,de Ana Maria Machado. Discutimos como esse processo de assimilação de um texto possibilita a dinamicidade da obra e sua transgressão. Os procedimentos metodológicos de análise pautam-se nos estudos de Genette (1997) que nos permitiram evidenciar como se compõe esse processo de escrita relacional.

\section{NO ZIGUEZAGUE ENTRE POEMAS, CARTAS, DIÁRIOS - A HISTÓRIA DE FELPO FILVA}

Lançado no ano de 2006 pela Editora Moderna, o livro Felpo Filva, de Eva Furnari, recebeu, no ano seguinte, em 2007, três grandes prêmios: Jabuti de melhor livro infantil, o FNLIJ, e "O Melhor Para Criança". O livro conta a história amorosa de Felpo e Charlô. Felpo Filva (personagem que dá nome ao livro) é um poeta muito tímido, conversa pouco com as pessoas, mal conhece seus vizinhos e nunca responde a nenhuma das cartas que recebe de seus fãs. Certo dia, um envelope lilás chamou 
sua atenção, no seu interior havia uma carta de uma fã chamada Charlô. A fã fazia críticas ao jeito triste que ele escrevia suas poesias, e sugeria que seus projetos literários fossem marcados por outras sensações e emoções que nos envolvem no cotidiano. Essa iniciativa de Charlô provocou uma troca de correspondências inusitada entre o escritor e a leitora. A história principal evoca um grande diálogo que a princípio se dá entre dois personagens: Felpo e Charlô.

À medida que as correspondências são ampliadas, os dois se percebem como pares, e esse relacionamento resvala para um final feliz: o casamento. A princípio, a sensação de que já vi e já li essa história é a mais latente, os personagens são animais que falam e vivem como seres humanos. Esse recurso denominado antropomorfização foi muito utilizado em fábulas e contos de fadas que circulavam no ocidente, tinham por objetivo transmitir de forma metafórica e inanimada valores religiosos, morais e sociais. Um enredo que poderia ser classificado como banal, mas que ganha vigor pelas intertextualidades visíveis na obra, provocando o leitor a ler aos saltos, deslizando pelos intertextos, pululando aqui e acolá.

Ao mergulhar na narrativa de Felpo Filva, percebe-se a convivência simultânea de diversos textos compondo uma tessitura que implica movimento no ato de ler. A intertextualidade é amplamente explorada, faz parte do corpo da narrativa que conjuga uma variedade de combinações. Essa variedade inclui muitos gêneros textuais que imbricados à narrativa constituem uma malha textual plural podendo ser tratada como um hipertexto. Essa arquitetura mais flexível, segundo Genette (1982), é todo texto que deriva de um texto anterior por transformação simples ou indireta. É, portanto, um texto que propõe uma leitura relacional, estimula o leitor a ler muitos outros textos em função de um outro, constituindo um "estruturalismo aberto" (GENETTE, 1982). Nesse sentido, o texto está referendado na citação, esta, por sua vez, possui função ambígua - 0 ato de colar outros textos promove a convivência da tradição, ao passo que constrói outro caminho para improvisar ou para recriar. A narrativa é, então, a transformação e a assimilação de vários outros textos, marcas da intertextualidade.

O personagem principal é um coelho, poeta e muito tímido que se apaixona por Charlô - uma crítica corajosa de suas poesias. O coelho possui nome, sobrenome e endereço, como qualquer ser humano. Toma remédio, lê bulas, manuais de instruções e utiliza tantos outros textos que, arquitetados na trama textual, ampliam as 
possibilidades de leitura. Essa forma de contar histórias, que envolve essa costura tão diversa de vários textos, propõe a quebra da linearidade pela multiplicidade textual. Nem mesmo a numeração encontrada no canto das páginas do livro, que por ora podem imprimir uma ideia de linearidade, implicam a estrutura desse texto multilinear.

A narrativa de Felpo Filva inicia tramando com a autobiografia de Felpo, forma artística que evoca memórias e sensações particulares de um personagem. Segundo Camargo e Santos (2010, p. 56), "[...] a autobiografia, mais do que um gênero literário, caracteriza-se pela construção do eu, construção que é singularização no social, não individualização. [..]", trata-se de um processo de interconstrução da história do sujeito com a história para além de uma escrita linear dos fatos e acontecimentos da sua vida. As citações, os nomes, os acontecimentos históricos narrados, os mais diversos elementos que o eu se defronta, marcam sua construção e evocam os muitos atores desse processo interpessoal e narrativo. $\mathrm{O}$ autor define certo eixo à narrativa. Com dimensão criativa, os textos autobiográficos contêm traços de ficcionalidade, e o autobiográfico torna-se personagem.

A escrita da autobiografia coloca o autor de forma introspectiva a suscitar o debate de problemáticas pessoais, políticas e sociais. Nessa perspectiva de cunho íntimo, que se revelam fatos da vida ao mesmo tempo em que se vive, a autobiografia é passível de estabelecer um vínculo entre a narrativa e o leitor. Por curiosidade ou interesse, o leitor lança-se no livro por um viés, a princípio, despretensioso.

Nessa narrativa muitos outros gêneros cruzam-se: bula de remédio, manual de instrução, bilhete, telegrama, poemas, livros, fábula, receita de doces, lista, provérbio, cartão postal, canção, conto e cartas com grande ênfase. Essa diversidade de gêneros forma uma trama textual por meio da articulação entre a linguagem verbal e visual. Ramos e Panozzo (2010, p. 18) diriam ainda que a renovação da literatura infantil contemporânea está para além do hibridismo verbo-visual, a nova literatura infantil é dotada de "[...] caráter literário, artístico, estético, cultural e comunicativo". A leitura tende a ser diferenciada. Pode-se saltar de um gênero ao outro, experimentar e sentir um percurso de leitura dinâmico.

Ramos e Panozzo (2010), em seu artigo Literatura infantil contemporânea: o passado (revestido) bate à porta, trazem à tona à importância do livro/da ficção como produto e produtor de uma memória individual e coletiva. O livro, portanto, "[...] é um 
Atos de Pesquisa em Educação - ISSN 1809-0354

Blumenau - vol. 11, n. 2, p.611-633 ago./nov. 2016

DOI: http://dx.doi.org/10.7867/1809-0354.2016v11n2p611-633

dos artefatos culturais que podem guardar a memória individual e coletiva das experiências de vida que alimentam a ficção e retomam à própria vida". (RAMOS; PANOZZO, 2010, p. 18). Nesse sentido, entendemos que uma das contribuições do texto de Felpo Filva é o registro da memória social, por meio dos diferentes gêneros e seus suportes.

Figura 1 - Citação de textos de vários gêneros textuais

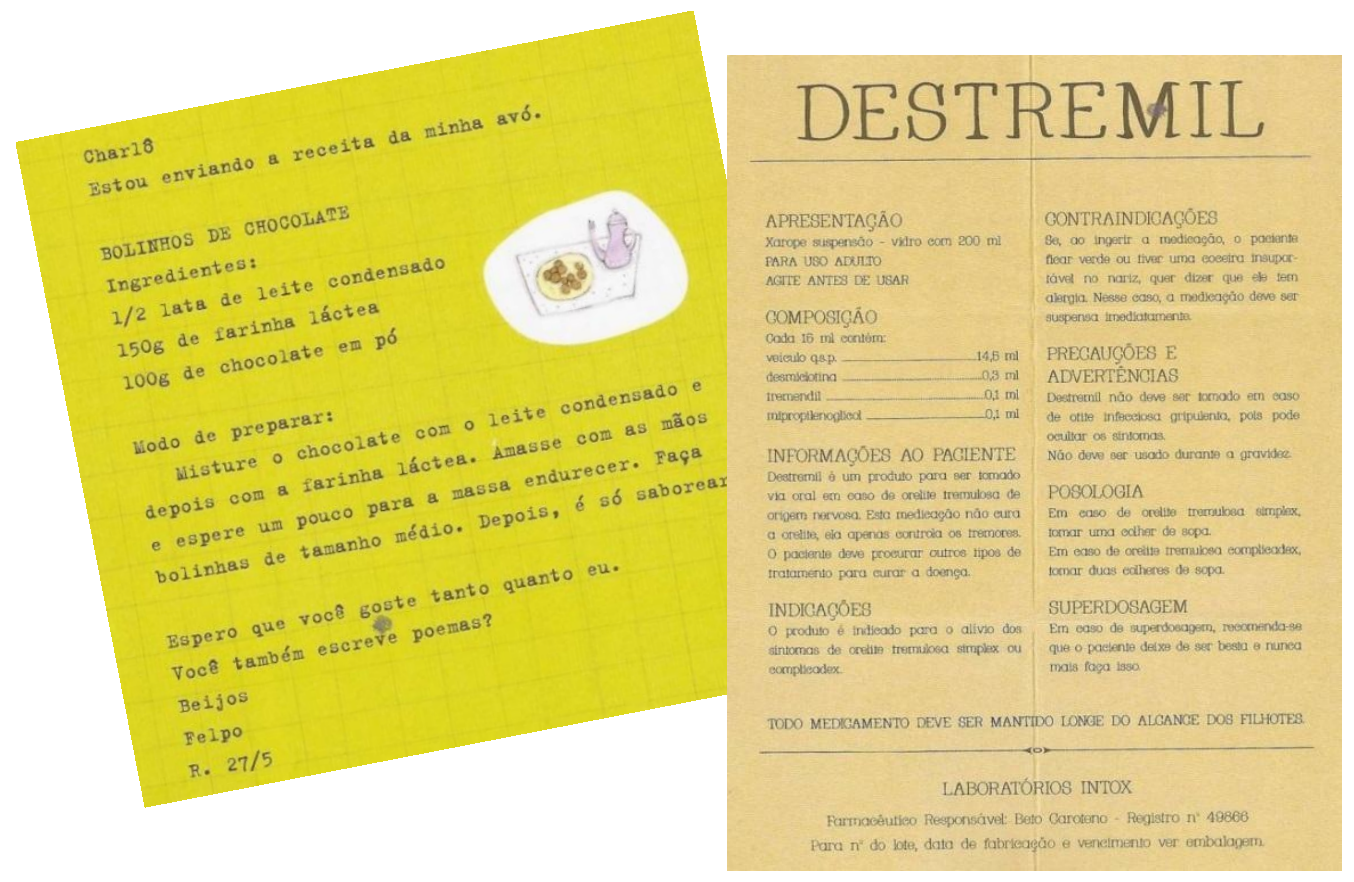

O texto de Felpo Filva segue revelando sua memória, porém de forma fragmentada e plural. A todo o momento surge uma forma de escrita que suscita tempos diferentes, histórias, arte, comunicação e linguagem. É um texto marcado por outros textos, aumentando, assim, sua potência em disparar reflexões e leituras múltiplas. É o fio condutor da intertextualidade que instaura uma forma diversa de escrever e de ler a literatura contemporânea. Exige um leitor atento e entregue à leitura, a fim de estabelecer relações, de participar do jogo, transitando entre os vários caminhos indicados pelos cruzamentos dos textos.

Estamos diante de um texto multilinear. É impossível pinçar um ponto de vista apenas, somente uma origem. Composto de textos de gêneros variados, a leitura resvala, faz-se em rede e esta é, segundo Barthes (1997), a marca plural de um 
Atos de Pesquisa em Educação - ISSN 1809-0354

Blumenau - vol. 11, n. 2, p.611-633 ago./nov. 2016

DOI: http://dx.doi.org/10.7867/1809-0354.2016v11n2p611-633

texto.Ao cotejarmos uma fábula moralizante e Felpo Filva,veremos que a fábula se destaca pela unicidade e seu princípio de decisão que configura um texto legível- texto este onde tudo está posto, começo-meio-fim. Na contramão, Barthes destaca o texto escrevível, que apresenta várias possibilidades de leitura, que é "a mão do leitor" escrevendo o próprio texto.

Essa convivência simultânea de muitos outros textos explícitos corrobora para o plural do texto, não centrado em um enredo que apresenta causa e consequência, mas que escapa por diversos textos que vão compondo a trama. É preciso desvelar enigmas. Nesse processo de leitura onde muitos pensares convivem, o leitor trabalha com uma gama enorme de sentidos que, muitas vezes, são opostos, o que implica em uma leitura reversível e exige um leitor não parasita. Para Barthes (1997), todo texto sugere linhas de fuga, porque a língua sempre é portadora de sentidos, é um sistema multivalente em que "os sentidos formigam"; a concretização destes sentidos está na execução, seja no ato de produção, no ato de ler, de contemplar, enfim na forma que cada um tem de produzir. E este texto de Eva Furnari nos privilegia com muitos pontos de fuga.

Generosamente Furnari (2006) presenteia o leitor com um estilo textual inusitado para literatura infantil. Essa narrativa diferencia-se do texto "legível", tradicional, porque é formado por um composto de textos de diversos gêneros textuais, blocos fragmentados e conectados, pontos multiplicados que se inter-relacionam em determinados pontos, formando uma espécie de rede por meio da qual passa todo o texto. Ele apresenta uma estrutura digressiva, e, portanto, reversível e não-linear, composta por sentidos articulados que sugerem diferentes entradas e saídas do texto.

Por meio da Dedicatória, a autora rompe com o uso normal atribuído a este tipo de texto. Ela não dedica a obra aos parentes, aos filhos ou aos grandes estudiosos como é comum, mas a todos aqueles que têm orelhas diferentes. Essa forma inusitada de começar a história por meio da dedicatória e da autobiografia é um dos recursos que tendem a aproximar o leitor da obra. A autobiografia, segundo Camargo e Santos (2010, p.55), "[...] é a possibilidade de escrita de si [...]", neste caso o autor-narrador aponta significado a experiências e coloca-se sob o olhar do leitor. É um texto aberto e possibilita um espaço para o leitor operar a escrileitura, processo este onde o leitor persegue palavras e expressões, estabelece relações e significa a obra. 
Ela inicia com um tema recorrente para a humanidade que são as "diferenças", porém de uma forma inovadora, divertida e lúdica. A forma envolve o leitor, sugerindo releituras e reflexões mais profundas acerca do eu com relação ao mundo. Esse livro remete-nos a um clima de acolhimento e paixão. Essa organização que se deu a partir de uma trama, com certa sequência temporal, Ihe dá um status de romance.

Ao longo da história, percebemos que os gêneros não estão dispostos hierarquicamente, pelo contrário, surgem à medida que a narrativa progride, e os fatos vão sugerindo a costura dos mais diversos gêneros textuais. A leitura-montagem torna-se, de certa forma, uma "brincadeira" divertida e séria ao mesmo tempo. De forma singular, a narrativa traz à tona a função social que cada texto tem no dia-a-dia das pessoas. As cartas na trama textual de Felpo Filva constituem um elemento marcante, são disparadoras de mensagens para além da comunicação pura e simples entre os sujeitos.

O uso de escrita epistolar, confessional, na literatura implica em uma narrativa que faz uso de testemunhos pessoais. São diversas cartas permeadas de mensagens poéticas, fabulosas, encantadas e até mesmo saborosas com receita de bolinhos de chocolate. Nesse sentido, Santos (2010) chama atenção para escrita epistolar não só como espaço de criação, mas como possibilidades de diversos percursos de leitura que pode ser realizada pelos mais diversos interlocutores.

$O$ ato de escrever uma carta constitui-se por ora uma abertura íntima, em que se desnudam informações que contribuem para a construção de um universo metafísico e relacional. A carta sugere um desabafo íntimo do escrito e torna-se veículo para transpor identidades. No tocante ao interlocutor, destaca-se a sensação de presentificação física do escritor. O manuseio da carta reporta o leitor ao cheiro, à cor, ao gosto das experiências, das sensações, das emoções; enfim o toque imaginário do outro. Estamos falando de um diálogo, a distância o alimenta. Da carta lacrada com selos diversos ao correio eletrônico, que via e-mail se faz necessário uma senha para acessar o texto da carta que é íntimo, por vezes confessional e literário.

A prática epistolar aproxima-se da literatura pelo seu caráter ficcional. De acordo com Rodrigues (2003, p. 23-24, grifos do autor), a troca de correspondências é '[...] 'lacunar', pois ela ajuda a compor um texto de natureza fragmentada, e esses fragmentos originam 'espaços' [...]". Espaços estes onde o leitor opera o seu percurso 
Atos de Pesquisa em Educação - ISSN 1809-0354

Blumenau - vol. 11, n. 2, p.611-633 ago./nov. 2016

DOI: http://dx.doi.org/10.7867/1809-0354.2016v11n2p611-633

de leitura, amplia sentidos e significados a cerca da obra e de si. Felpo Filva representa as trocas de correspondências quando de caráter literário, a construção estilística promove experiências de leitura diversas, por meio de uma costura de comentários sobre a vida (social, cultural e política), em um dado momento; enfim mudanças e atualidades que permeiam a vida. Entendemos que essa escritura que coloca em relevo as cartas é passível de aproximar o leitor do "[...] 'eu-epistolar', reconhecendo nele e nas suas atitudes aspectos do nosso próprio jeito de ser" (RODRIGUES, 2003, p. 24, grifo do autor).

$\mathrm{Na}$ figura 2 que segue, podemos observar uma das cartas que permeiam a narrativa.

Figura 2 - Carta de Charlô para Felpo

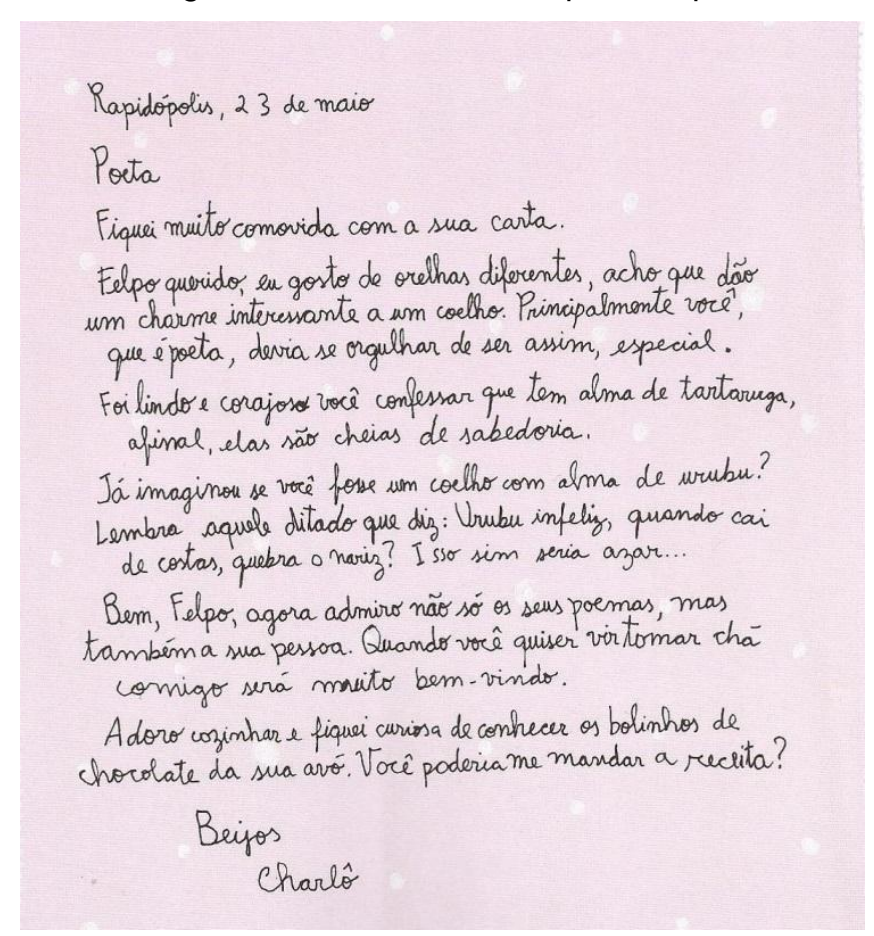

Fonte: Furnari (2006, p. 27).

Assim Felpo Filva constitui-se um texto plural, capaz de propor uma leitura mais interativa. A narrativa explora os mais diversos gêneros textuais, portanto oferece uma leitura mais ampla. Ao leitor cabe desvelar percursos de leitura diversos por meio da porosidade do texto, pelas suas lexias (BARTHES, 1997). Essa complexa construção que estabelece um texto plural, segundo Neitzel (2009), é "[...] um campo comum entre a intertextualidade e a interatividade, aberto às interferências do leitor [...]". Mesmo possuindo uma tessitura textual diferente, com inovações, a história de Felpo Filva, 
Atos de Pesquisa em Educação - ISSN 1809-0354

Blumenau - vol. 11, n. 2, p.611-633 ago./nov. 2016

DOI: http://dx.doi.org/10.7867/1809-0354.2016v11n2p611-633

aparentemente, segue de forma linear - inclusive a última página termina como nos contos de fadas mais tradicionais com início-meio-fim, com a palavra "Fim" e o casal trajado para o casamento.

Eis que o elemento surpresa surge: o livro não se encerra na página 37 , ele prossegue. Um P.S. vem logo depois, avisando que o fim da história amorosa entre Felpo e Charlô acabou, mas ainda não é o fim do livro, coloca o leitor em posição de estranhamento. Nas páginas seguintes (ver Figura 3), o leitor encontrará algumas curiosidades sobre a vida das personagens de forma poética, por vezes cômica e explicações sobre os gêneros textuais que atravessaram a história - tudo isso na voz de personagens apresentadas, nessas páginas, como parentes de Felpo e Charlô.

Figura 3 - Páginas após o fim da história
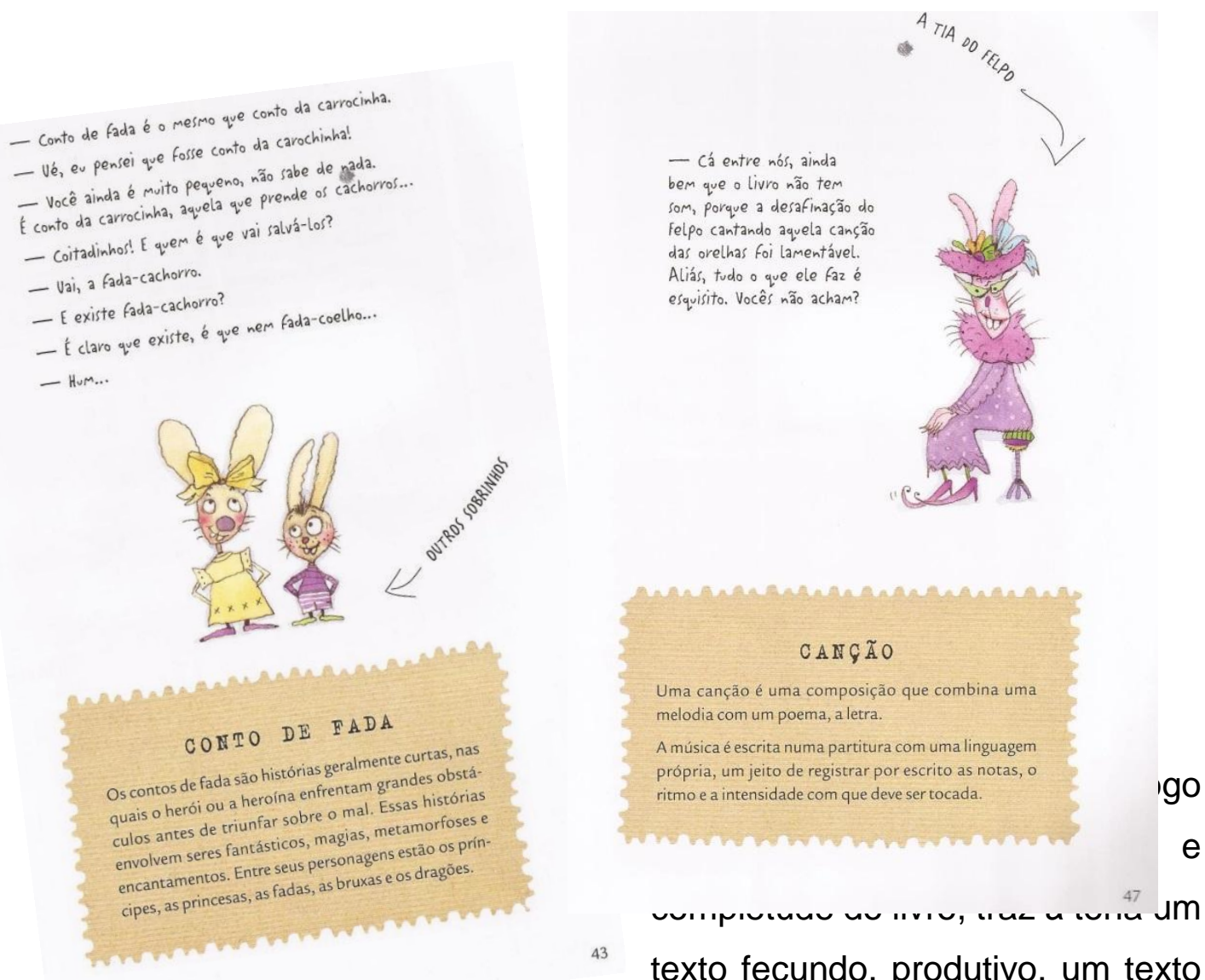

13 texto fecundo, produtivo, um texto que faz surgir muitos outros textos.

Esse texto fragmentado tende a estimular "[...] o leitor a perseguir cada nó que ele encontra reforçando a concepção de que o livro nunca é algo acabado, terminado pelo 
ponto final que o autor coloca na última linha, na última página" (NEITZEL, 2009, p. $55)$.

Temos, assim, uma narrativa transgressora, que foi tramada com uma justaposição de textos que, para Genette (1997), metaforicamente é chamada de palimpsesto, onde todas as obras têm origem em uma obra anterior, transformadas ou imitadas. Essa derivação está articulada, combinada, em conexão. A estratégia de lidar com os diversos personagens e suas histórias sugere um texto plural, cuja estrutura textual aberta coloca o leitor em estado de perda, pois ele precisa abandonar a narrativa principal para adentrar nos outros textos que permeiam a narrativa, operando conexões com outros textos, efetuando combinações entre os diversos gêneros textuais e linguagens.

Essa costura tão diversa é permeada por estratégias textuais como comparações, contradições e similitudes que provocam relatividade do significado, promovem uma leitura por associações. Nesse sentido, o leitor pode escolher o poema de Felpo ou a reescrita de Charlô. Na costura com a narrativa, tais estratégias textuais tornam a trama mais expressiva, concorrem, assim, para a abertura da obra, imprimem um grau de indeterminação e colaboram para o leitor operar vários percursos de leituras bem como abandonar uma leitura unívoca.

O livro contemporâneo, a exemplo de Felpo Filva, possui uma arquitetura textual que insurge em um conteúdo transgressor, o qual, do ponto de vista de Barthes (1997), salienta o convívio dos contrários - diferentes gêneros textuais que juntos, misturados e se tocando desobedecem a ordem dos textos tradicionais com iníciomeio-fim. Para Turchi (2008), a obra em debate é uma narrativa contemporânea, que intertextualiza a narrativa e os diversos gêneros textuais para além dos conflitos sociais, revela uma obra multifacetada que desconstrói o estabelecido e promove a ressignificação de paradigmas em um novo contexto.

Por fim, a narrativa contemporânea, segundo Turchi (2008, p. 3), "[...] mobiliza criativamente os escritores", é capaz de colocar em diálogo o novo e o velho em um texto plural, remetendo-nos a pensar os textos contemporâneos como desconstrução e construção do novo texto por um viés de paródia, de crítica, de paráfrases e muitos outros que tendem a revitalizar a literatura. Essa transformação do livro em uma outra 
obra artística, colabora para a formação estética e sensível de todos os envolvidos desde sua produção até a recepção.

\section{HISTÓRIA, LITERATURA E MÚSICA, ALÉM DO HORIZONTE EM ABRINDO CAMINHO}

Com a primeira edição lançada em 2001 pela editora Ática, o livro Abrindo Caminho, de Ana Maria Machado, tem como palimpsesto grandes clássicos da literatura, da música, da arte e da história mundial. O livro, voltado ao público infantojuvenil, encanta qualquer leitor que arrisque viajar entre as suas páginas. As ilustrações de Elisabeth Teixeira dialogam com o texto ampliando as possibilidades intertextuais. $O$ texto em análise articula múltiplas referências, faz alusão à história artística, política e cultural do mundo, promovendo, assim, a construção de uma trama intertextual por meio da citação indireta e da alusão. Os fragmentos costurados são citações indiretas que determinam uma escrita por associações, cria certo movimento na obra, por meio da permutabilidade de elementos que deslizam de um texto ao outro.

A obra foi vencedora dos prêmios FNLIJ Ofélia Fontes em 2004, na categoria O melhor livro para criança (Hors Concours), e prêmio Altamente Recomendável FNLIJ 2004, na categoria Criança (Hors Concours), ganhadora também do Hans Christian Abdersen - o prêmio máximo da literatura infantil mundial. O livro também foi selecionado para o catálogo White Ravens, Bolonha, 2005, prêmios que sinalizam a qualidade estética da obra.

Segundo Ana Maria Machado (2010), é mais que uma história, é uma narrativa que amalgama personagens importantes do passado, desbravadores que enfrentaram a selva, o deserto, o oceano, o céu; enfim, pessoas que transformaram obstáculos em caminhos, inimigos em amigos, fins em começos. De forma enigmática, a autora deixa em suspenso: Quais caminhos foram abertos? Quem são essas personagens? Quantos caminhos ainda são passíveis de serem abertos?

A narrativa gira em torno de seis personagens emblemáticas que são apresentadas ao leitor por meio do seu primeiro nome, estabelecendo, assim, uma aproximação; afinal Dante, Carlos, Tom, Cris, Marco e Alberto pode ser eu, você ou 
qualquer um. Eles vivem em busca de um caminho, uma realização pessoal, seus sonhos ao se realizarem afetaram a vida de muitos, abriram caminhos à humanidade. Temos uma narrativa que congrega vários enredos, vividos em épocas distintas, lugares e situações diferentes - são seis personagens que não se encontram, mas possuem muitas coisas em comum, caminhos, obstáculos e aventuras desbravadoras. Um texto que nos provoca a perceber as semelhanças entre Dante Alighieri, Carlos Drummond de Andrade, Tom Jobim, Cristóvão Colombo, Marco Polo e Alberto Santos Dumont. Em comum, podemos inferir que todos encontraram algo no meio do caminho: uma selva, uma pedra, um rio, um mar, um inimigo no deserto, um céu.

A intertextualidade é o que dá movimento à história, promovendo o diálogo entre uma obra e outra. Calvino (1990, p. 131) afirma ser esse o elemento que confere à literatura contemporânea a ideia de "enciclopédia aberta" e, portanto, uma narrativa que não se fecha sobre si mesma, mas se abre em um potencial de multiplicações de sentidos. Devido à estrutura multilinear que se destaca no diálogo entre vários textos, encontramos um texto plural e multifacetado; logo, essa forma de escrever redimensiona a leitura, sugere colocar o leitor em ação, pois exige montagem de fragmentos, abre espaço para desvendar enigmas e desvelar tramas; provoca uma leitura relacional e movimentada.

Ao longo da narrativa, é possível destacar alguns elementos do enredo como importante fonte provocativa de interação entre o leitor e o texto. A narrativa aparece em pequenos versos que estabelecem um diálogo com outras obras ou personagens reais e ficcionais, uma arca de palimpsesto que aponta, a cada página, um enigma, que nos remete a histórias clássicas e a grandes feitos. O leitor pega-se em um movimento de leitura e reflexão sobre as histórias do passado e o desenvolvimento do mundo. Temos uma narrativa gigante, que se constrói por meio de pequenos versos que provocam reflexões e diversos questionamentos acerca de histórias individuais e coletivas que alteraram formas de ser, de conhecer e de viver no mundo. O cruzamento de textos verbais e não verbais vai compondo um grande mosaico de citações.

Um processo criativo que se caracteriza pela montagem de fragmentos, consequentemente a escrita sugere uma leitura desafiadora e multilinear, a ampliação 
Atos de Pesquisa em Educação - ISSN 1809-0354

Blumenau - vol. 11, n. 2, p.611-633 ago./nov. 2016

DOI: http://dx.doi.org/10.7867/1809-0354.2016v11n2p611-633

dos sentidos pulula do texto, da ilustração, do percurso de leitura escolhido pelo leitor. Em todos os versos, as palavras iniciais repetem-se - fixam o tema central de caminhos a serem desbravados.

Ao final de cada verso, observamos que o obstáculo de Dante é a selva; de Carlos, a pedra; e de Tom, o rio (ver Figura 4). A sequência de versos tende a instaurar um enigma, ou um jogo de palavras a ser desvelado, pois se refere às personagens pelo primeiro nome e o obstáculo a ser superado, porém traz à tona que todos têm em comum um caminho a seguir. A leitura é diferente para quem sabe que em $A$ Divina Comédia, Dante Alighieri encontrou uma selva escura, na qual é atacado por animais ferozes.

Figura 4 - A selva, a pedra e o rio

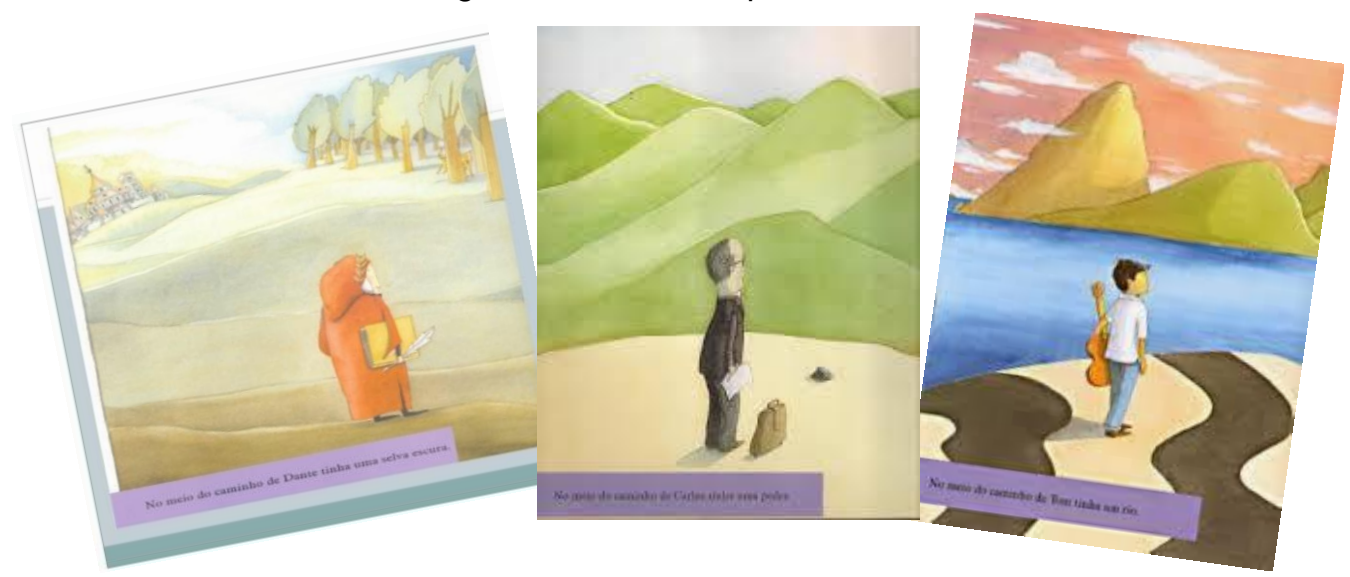

Fonte: Machado (2010, p. 5,7,9).

Nessa perspectiva, o livro é sempre movimento quando joga com suas possibilidades intertextuais. Diante delas, cabe ao leitor unir as partes, ampliando a potência do texto pelas aberturas efetuadas com a introdução de novos textos, visivelmente lá presentes, oferecendo uma movimentação mental. Ao tergiversar o texto, deslizamos de Machado para Alighiere.

Quando eu me encontrava na metade do caminho de nossa vida, me vi perdido em uma selva escura, e a minha vida não mais seguia o caminho certo. Ah, como é difícil descrevê-la! Aquela selva era tão selvagem, cruel, amarga, que a sua simples lembrança me traz de volta o medo. Creio que nem mesmo a morte poderia ser tão terrível. Mas, para que eu possa falar do bem que dali resultou, terei antes que falar de outras coisas, que do bem, passam longe. A Divina Comédia - Inferno - Canto I. (ALIGHIERI, 2003, p. 17). 
Uma narrativa infantil que encerra a proposta de Ítalo Calvino (1990) de um romance como grande rede, que tende para a multiplicidade dos sentidos, e, por isso, não se encerra na individualidade de um único autor. Nesse sentido, esta é uma obra que apresenta uma cartografia coletiva, cujos personagens colaboram para 0 processo de apagamento de autoria única, que dá passagem a muitos outros universos. Entretanto, no meio do caminho de Carlos, havia uma pedra:

\author{
No meio do caminho \\ Carlos Drummond de Andrade \\ No meio do caminho tinha uma pedra \\ Tinha uma pedra no meio do caminho \\ Tinha uma pedra \\ No meio do caminho tinha uma pedra. \\ Nunca me esquecerei desse acontecimento \\ $\mathrm{Na}$ vida de minhas retinas tão fatigadas. \\ Nunca me esquecerei que no meio do caminho \\ Tinha uma pedra \\ Tinha uma pedra no meio do caminho \\ No meio do caminho tinha uma pedra.
}

Era pau, era pedra, era o fim do caminho? Da literatura passamos à música. A dedicação do livro vai para Antônio Carlos Jobim (Tom Jobim), e a autora vai ao encontro de uma grande obra do autor, Águas de Março. Na rede textual de Tom Jobim reside o significante "rio", talvez seu obstáculo de vida. A paráfrase da poética da música de Tom Jobim articulada com a ilustração faz alusão às obras literárias musicais e às marcas delas na sociedade dos três primeiros personagens mencionados em Abrindo caminho.

Figura 5 - Trecho que remete a música de Tom Jobim 


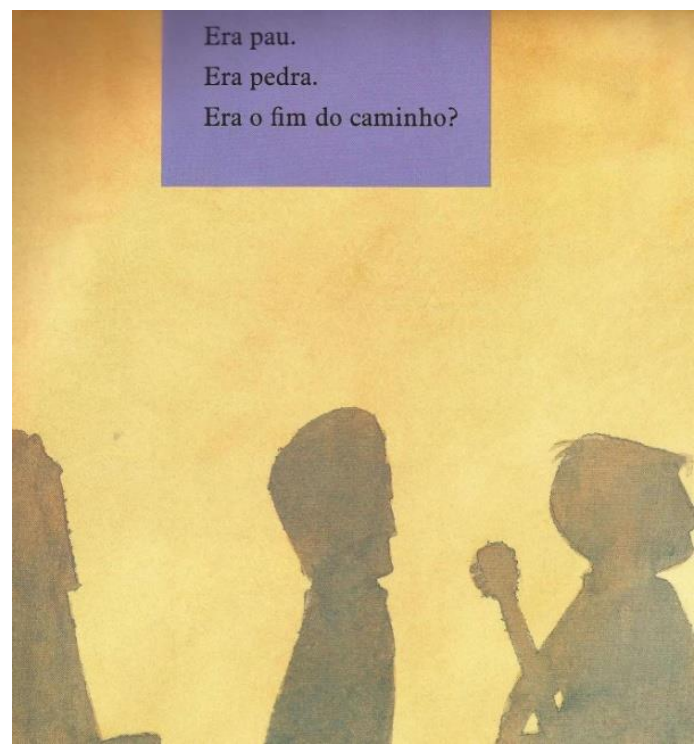

Fonte: Machado (2010, p. 10).

Entre idas e vindas, as histórias cruzam-se e as personagens compartilham um mesmo enredo, uma convivência que as coloca lado a lado. A autora apresenta as personagens de forma poética. O leitor, em um de seus percursos de leitura, pode perceber que o mar não era tão grande e monstruoso assim para Cris, e, pensando assim, Cristóvão Colombo partiu em direção à América.

O grande navegador aparece para ativar o mito do descobridor, como o personagem que realizou a ultrapassagem dos limites de um mapa antigo que desconhecia o que havia além do horizonte, em busca do novo, do encontro com um mundo esférico, no limbo do grande oceano. As viagens são enredadas literalmente pela autora que faz alusão à aventura do homem para desbravar e adequar-se ao mundo.

Se o mar foi o espaço de grandes descobertas, também os céus são lembrados diante do desafio que o homem se colocou de explorar para além do já conhecido. Se Cristóvão é citado quando o assunto é navegação, Albert Santos Dumont é o ícone lembrado quando o assunto é o sonho de voar como os pássaros - bem como a conquista do ar com a invenção do avião. E o céu não era o limite para Alberto, que se transformou no grande Santos Dumont - diminuiu distâncias e saudades, tornandose o pai da aviação, um salto para a modernidade.

No jogo intertextual de Abrindo Caminho, as articulações da história da humanidade, das artes plásticas, dos descobrimentos e das grandes invenções são 
Atos de Pesquisa em Educação - ISSN 1809-0354

Blumenau - vol. 11, n. 2, p.611-633 ago./nov. 2016

DOI: http://dx.doi.org/10.7867/1809-0354.2016v11n2p611-633

costuradas por uma narrativa verbo-visual, que dá pistas de leitura e amplia o potencial da obra. Dumont aparece para ativar a dobra das grandes invenções, quer diminuir distâncias, imitar os pássaros e voar sobre o mundo. Lúdica e poeticamente a autora confere a Dumont o feito da aviação, do voo e da ousadia do inventor para criar asas e romper a lonjura.

Por fim, Marco Polo, pouco a pouco, ia descobrindo novos caminhos e a si mesmo; despertou de um sono medieval e enfrentou abismos, montanhas, geleiras, desertos e relatou, ao mundo, o que era o oriente, em uma época em que a comunicação entre países e continentes dependia de cartas que eram levadas por mensageiros ou ainda eram dependentes do relato oral. Considerado um dos grandes exploradores do mundo, Marco Polo entra nessa narrativa trazendo à tona sua capacidade de contar histórias frente ao grande Kublai Khan. Também Calvino em Cidades Invisíveis apresenta Marco Polo como personagem que traz ao grande Khan sua percepção sobre os reinos visitados.

De agora em diante, vou descrever as cidades e você verificará se elas realmente existem e se são como eu as imaginei. Em primeiro lugar, gostaria de perguntar a respeito de uma cidade construída em degraus, exposta ao siroco, num golfo em forma de meia-lua. Vou relatar algumas das maravilhas que ela contém: um tanque de vidro alto como uma catedral para acompanhar o nado e o vôo das andorinhas e desejar bons augúrios; uma palmeira que toca uma harpa com as folhas ao vento; uma praça contornada por uma mesa de mármore em forma de ferradura, com a toalha também de mármore, preparada com comidas e bebidas inteiramente de mármore. (CALVINO, 1999b, p. 43).

Nessa perspectiva associativa, quando lemos Abrindo Caminho estabelecemos conexão também com Cidades Invisíveis, e uma história passa a ser o palimpsesto de outra história, revelando a interferência de uma escrita sobre a outra, exemplificando como um texto pode ser o referente para ler-se o outro: "Cette duplicité d'objet, dans l'ordre des relations textuelles, peut se figurer par la vieille image du palimpseste, où l'on voit, sur le même parchemin, un texte se superposer à un autre qu'il ne dissimule pas tout à fait, mais qu'il laisse voir par transparence" (GENETTE, 1982 , p. 556) ${ }^{1}$. Genette afirma que a ideia do palimpsesto encaminha-nos à utopia

\footnotetext{
1 "Essa duplicidade do objeto, na ordem das relações textuais, pode ser vista pela velha imagem do palimpsesto, que nos mostra, no mesmo pergaminho, um texto sobreposto ao outro que não se esconde completamente, mas que se deixa ver pela transparência" (GENETTE, 1982, p. 556, tradução nossa).
} 
Atos de Pesquisa em Educação - ISSN 1809-0354

Blumenau - vol. 11, n. 2, p.611-633 ago./nov. 2016

DOI: http://dx.doi.org/10.7867/1809-0354.2016v11n2p611-633

borgiana de uma literatura em transfusão perpétua, de forma que todos os livros possam ser percebidos como um único grande livro assim como todos os autores possam estar presentes em um único autor, alimentando a ideia do livro infinito e da autoria coletiva.

$\mathrm{Na}$ construção intertextual, abre-se a possibilidade de inúmeras relações e interconectividades entre as páginas do livro e, principalmente, fora dele, se assim o leitor desejar. Neitzel (2009, p. 21) afirma: "Esse processo de interconectividade compõe uma visão atomizada da literatura, uma literatura enquanto processo que se constrói mediante as intervenções do leitor". O leitor, assim, precisa assumir uma postura ativa, ele constrói sentidos e multiplica a significação da narrativa em um processo de "coautoria" ao longo da leitura. Durante toda a narrativa, percebemos que de cada verso e de cada personagem espraia-se um enigma. Nas mãos do leitor que aceita ser desafiado, a narrativa abre-se, torna-se um texto plural e flexível a partir das interferências do leitor.

O enredo de Abrindo Caminho (MACHADO, 2010) é escrito a partir de outras histórias. Os nomes das personagens servem como links para outros percursos de leitura e fica sob a responsabilidade do leitor ir ou não em busca desses outros significados. Neitzel (2009) defende que há casos em que o grau de explicitação da intertextualidade é maior do que de outros. Percebemos que a intertextualidade em Abrindo Caminho surge do cruzamento de várias histórias, uma intervenção perceptível, com considerável grau de explicitação.

Independentemente do caso, Neitzel (2009, p. 17) afirma, tendo em vista o conceito desenvolvido por Julia Kristeva, que: "a intertextualidade se constitui como um trabalho de transformação e assimilação de vários textos". A autora ainda afirma que, quando a intertextualidade é visivelmente intencional, como é o caso da obra aqui analisada, o texto torna-se plural. No que tange à malha intertextual, a narrativa tem imbricados, imagens, música, memórias, viagens, caminhos, que mais parecem um recorte-colagem na construção textual.

Do ponto de vista de Genette, Abrindo caminho tem sua narrativa marcada por uma intertextualidade mais implícita, a escolha da autora do entrecruzamento de outros textos é feita por alusão, invoca potencialmente outros textos. Estamos, 
Atos de Pesquisa em Educação - ISSN 1809-0354

Blumenau - vol. 11, n. 2, p.611-633 ago./nov. 2016

DOI: http://dx.doi.org/10.7867/1809-0354.2016v11n2p611-633

portanto, diante de uma escrita relacional, em que uma obra deriva de uma anterior em um momento manifesta, em outro, secreta, com outros textos para re-significação e aproveitamento de um material pré-existente para compor outro, nesse caso singular e contemporâneo.

Essa construção intertextual da narrativa materializa-se a partir do momento em que o leitor aceita o desafio de saber quem é Dante, que pedra é essa que está no caminho de Carlos, de que rio está falando a autora. Segundo Neitzel (2009), não basta folhear o livro e decodificar os códigos, é preciso avançar na leitura e superar

[...] os limites impostos pela língua, pelo escritor, pelo próprio texto, porque a atribuição de sentido dependerá da postura do leitor, a ambiguidade da obra só é mantida quando ele se entrega à leitura como expansão, e, para isso, é necessário operar o retalhamento do texto, violar suas verdades. (NEITZEL, 2009, p. 183).

A ideia do livro labirinto de Jorge Luis Borges (1999), do conto A Biblioteca de Babel, é revisitada não só por meio do texto verbal, mas também das ilustrações. Um livro dentro de outro livro é a imagem que colhemos. A evocação de uma realidade cujo mundo é composto por uma biblioteca sem fim, que abriga uma infinidade de livros. Ao folhear as páginas é possível perceber a presença de outros livros, outras personagens, outras narrativas; histórias que se cruzam fazendo alusão a fatos de várias épocas.

Ao longo do texto de Borges (1999), podemos perceber, sentir e ler o cruzamento de várias histórias dentro da narrativa atual, e a ilustração da página 12 retrata uma garotinha confortavelmente lendo o livro em debate perto de uma estante repleta de diversas referências, imagem que simboliza como um texto se remete a outro texto em um processo infinito de diálogo com outros textos, uma estrutura mise en abyme. Esta está relacionada à pretensão de mostrar as influências sobre as quais estão calcadas toda escrita. A estrutura mise en abyme atribui características labirínticas ao texto. Ela oferece ao leitor um texto que remete a outro texto, expondoo a um movimento constante de ressignificações, situando-se nos corredores da Biblioteca de Babel (NEITZEL, 2009). A construção intertextual permite que a narrativa se volte sobre si mesma. Neitzel (2009) e Wandelli (2003) sinalizam que, por meio da estrutura mise em abyme, a narrativa constitui-se pela multiplicação de livros e conexões simultâneas. 
Além desse recurso, as ilustrações concorrem para ampliar o potencial intertextual da obra. Segundo Ramos e Nunes (2013, p. 261), a ilustração "[...] concede ao leitor uma porta para ele abrir e ingressar na história". Nas imagens da maioria das páginas, a ilustradora utiliza uma estratégia visual que apresenta características que lembram mais de uma personagem na mesma imagem. As ilustrações não apenas descrevem o que está escrito, mas exploram o texto enigmático, as imagens conversam com a história e dão pistas de inúmeras referências que podem ser encontradas. $\mathrm{Na}$ composição, estão entrelaçados $\mathrm{o}$ homem oriental de Marco Polo, o pássaro dos céus de Alberto Santos Dumont, o monstro marinho de Cristóvão Colombo. Todas as personagens são viajantes que saem de um determinado lugar - nem sempre com um roteiro a seguir. Uma viagem para a qual o leitor está convidado.

Abrindo caminho é marcada por textos que potencializam a escrita porque são textos tecidos com outros textos em uma grande malha intertextual. Sua leitura pode ser incômoda, desconfortável, pois se trata de uma leitura multilinear, que propõe atos de interconectividade que tendem a ampliar o texto, sem chaves de leitura. É preciso entrega e disposição para entrar em uma leitura como esta, relacional e dinâmica. $O$ texto implica, dessa forma, viagens descontínuas e incertas no tempo e no espaço, oferecendo ao leitor mirim um percurso dinâmico de leitura, que lhe exigirá uma leitura produtiva. Apesar de ser uma obra que é composta de versos curtos, sua porosidade é alta por conta das relações intertextuais propostas. Kristeva anuncia esse tipo de texto como produtividade, como algo que está por ser feito, e que, portanto, se concretiza pela permutação com outros textos entrelaçados. E o leitor, como um produtor de significações.

\section{CONSIDERAÇÕES FINAIS}

Enfim, ao longo da história, não esquecendo de sua estrutura de origem e funções, o livro se transfigura porque reflete mudanças, inquietudes e tendências.

Flávia Brocchetto Ramos e Ana Paula Mathias de Paiva 
Dentre os livros analisados em nossa pesquisa, identificamos que ambas as obras são marcadas pelos intertextos, bem como pelo convívio simultâneo de vários gêneros. Tanto Abrindo caminho como Felpo Filva evocam intertextos, colocando o leitor, se assim o quiser, em diálogo com outros textos.

É possível perceber como a intertextualidade expande o potencial dessas obras, já que seu fundamento é um texto que se constrói pelo recorte-colagem de outros textos, por meio da imitação, da paródia, da citação direta ou indireta, do plágio, das traduções, da reminiscência, do paratexto, do pastiche, das alusões, das críticas, das paráfrases, entre outros. As obras se apresentam como textos abertos às plurissignificações, multilineares e escrevíveis; textos que geram múltiplos percursos de leitura e variedades interpretativas.

Guiadas pela classificação de Genette para análise das obras, o qual entende a intertextualidade pela transformação ou assimilação de outros textos, os quais acabam por revelar as marcas que atestam a presença de outros textos, retornarmos ao nosso problema de pesquisa: Como essas obras exploram a intertextualidade? Como cada uma promove o entrecruzamento de vários textos?

Observamos que na narrativa de Felpo Filva a intertextualidade é explícita, isto é, por meio da citação direta de um grande sortido de gêneros textuais, a obra sugere a multiplicação de interpretações e não se fecha na última página. Ela deixa pistas sugestivas para leituras futuras. $O$ texto tende, assim, a promover uma leitura mais interativa, ao passo que a leitura vai exigindo uma montagem de fragmentos, uma coautoria para aumentar a rede de relações que a escritura propõe.

Em Abrindo caminho, por exemplo, a intertextualidade evoca outros textos por citação indireta e alusão, utilizando a ilustração do texto como marca que evidencia esse diálogo. Articulada a esse texto modular, as ilustrações potencializam significados e expressões muitas vezes para além do texto.

Logo temos duas obras marcadas pela exploração da intertextualidade que se colocam em diálogo com outras obras, provocando o leitor a movimentos produtivos de ressignificação da obra, introduzindo o leitor mirim em um processo dinâmico. $A$ obra percebida como objeto estético propõe uma leitura relacional, rica e aberta a plurissignificações. O leitor mirim não é, dessa forma, subestimado, mas valorizado. Obras como essas nos permitem pensar a prática da leitura como brincadeira, 
Atos de Pesquisa em Educação - ISSN 1809-0354

Blumenau - vol. 11, n. 2, p.611-633 ago./nov. 2016

DOI: http://dx.doi.org/10.7867/1809-0354.2016v11n2p611-633

premissa fundamental para qualquer programa de formação de leitores. "Apreciar, portanto, não deve ser associado a um ócio inútil, posto que constitui uma arte de ler, inclui atividade mental, é um veículo de expressão de ideias e de acesso a entendimentos" (RAMOS; PAIVA, 2014, p. 436).

\section{ELAINE CRISTINA DA SILVA MARTINS}

Doutoranda do Programa de Pós-Graduação em Educação da Universidade do Vale do Itajaí - UNIVALI

\section{ADAIR DE AGUIAR NEITZEL}

Professora do Programa de Pós-Graduação Mestrado e Doutorado em Educação da Universidade do Vale do Itajaí - UNIVALI. Linha de Pesquisa: Cultura,Tecnologia e Processos de Aprendizagem.

\section{ALINE AMARAL FREITAS}

Mestranda do Programa de Pós-Graduação da Universidade do Vale do Itajaí UNIVALI

\section{REFERÊNCIAS}

ALIGHIERI, D. A divina comédia. E-Books Brasil. Tradução José Pedro Xavier Pinheiro. São Paulo: Atena, 2003.

BARTHES, R. S/Z - uma análise da novela Sarrasine de Honoré de Balzac. Tradução Léa Novaes. Rio de Janeiro: Nova Fronteira, 1997.

BORGES, J. L. Obras completas de Jorge Luis Borges - volume 1. São Paulo: Globo, 1999.

CALVINO, I. Seis propostas para o próximo milênio: lições americanas. Tradução: Ivo Cardoso. São Paulo: Companhia das letras, 1990.

Se um viajante numa noite de inverno. Tradução de Nilson Moulin. São Paulo: Companhia das Letras, 1999a.

Letras, $1999 \mathrm{~b}$.

As cidades invisíveis. Tradução Diogo Mainardi, São Paulo: Companhia das

CAMARGO, M. R. R. M. (Org.); SANTOS, V. C. C. (Col.). Leitura e escrita como espaços autobiográficos de formação. São Paulo: UNESP; São Paulo: Cultura Acadêmica, 2010.

FURNARI, E. Felpo Filva. São Paulo: Moderna, 2006.

GENETTE, G. Palimpsestes: la littérature au second degré. Paris: Seuil, 1982. 
Atos de Pesquisa em Educação - ISSN 1809-0354

Blumenau - vol. 11, n. 2, p.611-633 ago./nov. 2016

DOI: http://dx.doi.org/10.7867/1809-0354.2016v11n2p611-633

Paratexts: thresholds of interpretation. Tradução Jane E. Lewin. Cambridge: Cambridge University Press, 1997.

MACHADO, A. M. Abrindo Caminho. São Paulo: Ática, 2010.

NEITZEL, A. de A. O jogo das construções hipertextuais. Florianópolis: UNIVALI, 2009.

RAMOS, F. B.; PANOZZO, N. S. P. Literatura infantil contemporânea: o passado (revestido) bate à porta. Estudos de Literatura Brasileira Contemporânea, Brasília, n. 36, p. 17-29, jul./dez. 2010.

RAMOS, F. B.; NUNES, M. F. Efeitos da ilustração do livro de literatura infantil no processo de leitura. Educar em Revista, Curitiba, Brasil, n. 48, p. 251-263, abr./jun. 2013.

RAMOS, F. B.; PAIVA, A. P. M. de. A dimensão não verbal no livro literário para criança. Revista Contrapontos [online], Itajaí, v. 14, n. 3, p. 425-447, set./dez. 2014.

RODRIGUES, L. G. Uma leitura do modernismo: cartas de Mário de Andrade e Manuel Bandeira. Rio de Janeiro: PUC, Departamento de Letras, 2003.

SANTOS, V. C. C. Fazeres autobiográficos e cartas pessoais. In: CAMARGO, M. R. R. M. (Org.); SANTOS, V. C. C. (Col.). Leitura e escrita como espaços autobiográficos de formação. São Paulo: UNESP; São Paulo: Cultura Acadêmica, 2010.

TURCHI, M. Z. Tendências atuais da literatura infantil brasileira. In: CONGRESSO INTERNACIONAL DA ABRALIC, 9. - Tessituras, Interações, Convergências, 2008, São Paulo. Anais eletrônicos. São Paulo: USP, 2011. Disponível em: <http://www.abralic.org.br/download/anaiseventos/cong2008/AnaisOnline/simposios/ pdf/047/MARIA_TURCHI.pdf>. Acesso em: 11 jun. 2015.

WANDELLI, R. Leituras do hipertexto: viagem ao Dicionário Kazar. Florianópolis: UFSC; São Paulo: Imprensa Oficial do Estado de São Paulo, 2003. 